\title{
Current view of neoadjuvant chemotherapy in primarily resectable pancreatic adenocarcinoma
}

\author{
Minireview
}

Michal EID ${ }^{1, *}$, Lenka OSTŘÍŽKOVÁ ${ }^{1}$, Lumír KUNOVSKÝ ${ }^{2,3}$, Dagmar BRANČÍKOVÁ ${ }^{1}$, Zdeněk KALA ${ }^{2}$, Jan HLAVSA ${ }^{2}$, Pavel JANEČEK², Ivana KOSÍKOVÁ ${ }^{1}$, Monika BLAŽKOVÁ ${ }^{1}$, Ondřej SLABÝ ${ }^{4,5}$, Jiří MAYER $^{1}$

${ }^{1}$ Department of Hematology, Oncology and Internal Medicine, University Hospital Brno, Faculty of Medicine, Masaryk University, Brno, Czech Republic; ${ }^{2}$ Department of Surgery, University Hospital Brno, Faculty of Medicine, Masaryk University, Brno, Czech Republic; ${ }^{3}$ Department of Gastroenterology and Internal Medicine, University Hospital Brno, Faculty of Medicine, Masaryk University, Brno, Czech Republic; ${ }^{4}$ Department of Biology, Faculty of Medicine, Masaryk University, Brno, Czech Republic; ${ }^{5}$ Central European Institute of Technology, Masaryk University, Brno, Czech Republic

${ }^{*}$ Correspondence: eid.michal@fnbrno.cz

Received April 8, 2020 / Accepted August 12, 2020

\begin{abstract}
Pancreatic ductal adenocarcinoma (PDAC) is now the 11th most common cancer and in 2018 there were 458,918 new cases worldwide. In the Czech Republic, a total of 2,173 patients were diagnosed in 2015, ranking the second in incidence worldwide. In contrast to other malignancies, recent research has not brought any major breakthrough in the treatment of PDAC and hence the prognosis remains very serious. Radical resection is the only curative approach, but after the initiation of the standard pathological evaluation of the resected tissue, according to the Leeds protocol, $80 \%$ of the resections are R1 (resections with microscopically positive margins). The results of studies in patients with borderline resectable or locally advanced PDAC prefer neoadjuvant chemotherapy or chemoradiotherapy. This approach leads to a higher number of radical R0 resections and better survival. For neoadjuvant treatment in patients with primarily resectable PDAC, most results come from retrospective analysis or phase II trials. However, recently, data from three randomized clinical trials with neoadjuvant therapy for resectable PDAC were presented. These results support the use of chemotherapy or chemoradiotherapy prior to surgery. In the trials published to date, there are differences in chemotherapeutic regimens, cytostatic doses, and the definition of resectability. Thus, up-front resection with adjuvant chemotherapy is still the standard of care and a well-designed randomized trial using neoadjuvant therapy is now necessary.
\end{abstract}

Key words: pancreas, carcinoma, resectable, neoadjuvant, treatment

The most common histological type of pancreatic tumor is pancreatic ductal adenocarcinoma (PDAC) and this accounts for nearly $90 \%$ of all pancreatic tumors [1]. Based on the GLOBOCAN 2018 data, PDAC is the 11th most common cancer and in 2018458,918 new cases and 432,242 deaths were reported worldwide [2]. In the Czech Republic, the incidence rate for pancreatic cancer is alarming and is the second-highest globally; in 2015 it was 20.82 per 100,000 . Mortality is still high, 18.58 per 100,000 inhabitants, and almost copies the incidence curve [3]. Parallel with the increasing incidence of risk factors for PDAC, such as obesity, type II diabetes, smoking, and alcohol intake, the incidence of PDAC is increasing [4]. Over the past 30 years, the 5-year overall survival (OS) rate has increased from $2 \%$ to $9 \%$ regardless of disease stage [5]. Radical resection is the only potentially curative approach. According to the NCCN resectability criteria, primary resection is indicated in only $10-20 \%$ of patients with PDAC, where contact or invasion of the vascular structures has not been identified. However, the relatively high postoperative morbidity rate, which may reach $66.2 \%$ within 90 days after resection, must be considered in making the treatment decision [6]. Moreover, in $46-89 \%$ of patients, relapse is observed [7]. Most relapses are diagnosed within 2 years after resection, of which approximately $20 \%$ are within the first 6 months. Median recurrence-free survival is 11.7 months $[8,9]$. 
Only a minority of patients are detected in the early stage of the disease when the risk of dissemination is lowest. There is no recommended population-based screening program and only patients at high risk of developing PDAC are checked regularly. This group includes patients with genetic risks such as Peutz-Jeghers syndrome, familial melanoma syndrome, Lynch syndrome, or BRCA 1, 2 mutation carriers. However, this covers only $10 \%$ of patients [10].

In recent years, there has been some development in the comprehensive treatment of resectable and borderline resectable PDAC. In primarily resectable tumors, resection followed by adjuvant chemotherapy for 6 months is still considered as the standard of care. However, according to NCCN guidelines, neoadjuvant therapy can already be considered in patients with resectable tumors and with risk factors such as large primary tumors, enlarged lymph nodes, high baseline CA 19-9 levels, significant weight loss, or severe pain [11]. Forty-six percent of patients do not receive systemic adjuvant therapy, particularly due to severe postoperative complications, poor clinical status, comorbidities, or early disease recurrence $[12,13]$. The average time from diagnosis to the initiation of adjuvant treatment is 2-3 months [14]. Pancreatic cancer is an aggressive disease with a tendency to disseminate in its very early stages. Using mathematical models, Haeno et al. found that tumors with a diameter of $1 \mathrm{~cm}, 2 \mathrm{~cm}$, and $3 \mathrm{~cm}$ had a probability of micrometastatic dissemination of $28 \%$, $73 \%$, and $94 \%$ at the time of diagnosis. These models were confirmed by autopsy [15].

\section{Methods}

To identify trials for neoadjuvant and adjuvant treatment, a comprehensive search of Clinical trials, Cochrane, Embase, and MEDLINE was performed. Articles were selected based on relevance to our objectives. Search terms included "neoadjuvant," "adjuvant," "gemcitabine," "FOLFIRINOX," "folinic acid," "fluorouracil," "irinotecan," "oxaliplatin," "radiotherapy," "chemoradiotherapy," "resectable," "pancreatic cancer," "drug combination". Only articles written in English were assessed. A selection was made for prospective and retrospective phase I, II, and III trials, and publication dates from 1998 to 2020 .

\section{The current standard of care for resectable PDAC}

In 2004, Neoptolemos et al. presented the results of the ESPAC- 1 trial with a $2 \times 2$ factorial design. This study compared adjuvant 5-fluorouracil (5-FU)-based chemoradiotherapy alone (arm A), adjuvant 5-FU based chemoradiotherapy followed by 5-FU (arm B), adjuvant 5-FU alone (arm C), and observation alone ( $\operatorname{arm} \mathrm{D})$. Survival was significantly longer in patients who received chemotherapy compared to patients who did not, with a median overall survival (mOS) 20 vs. 16 months (hazard ratio $[\mathrm{HR}]=0.71 ; \mathrm{p}=0.009$ ). Further- more, patients with chemoradiotherapy had a mOS 16 vs. 18 months as compared to patients who did not receive chemoradiotherapy $([\mathrm{HR}]=1.28 ; \mathrm{p}=0.05)[16]$. Thus, in this trial, no benefit of adjuvant chemoradiotherapy was observed.

In 2007, the CONKO-001 trial compared surgical resection with observation vs. resection followed by adjuvant chemotherapy for 6 months with gemcitabine. In the gemcitabine group, disease-free survival (DFS) was 13.4 vs. 6.7 months $(\mathrm{p}<0.001)$ [17]. In 2013, a long-term follow-up confirmed the superiority of the adjuvant chemotherapy arm. The mOS was 22.8 vs. 20.2 months $([\mathrm{HR}]=0.76)$, 5 -year OS was $20.7 \%$ vs. $10.4 \%(\mathrm{p}=0.01)[18]$.

The ESPAC-4 trial compared two adjuvant regimens, a combination of gemcitabine and capecitabine versus gemcitabine monotherapy for 6 months. A total of 792 patients were divided into both arms at a 1:1 ratio. The mOS was 28.0 vs. 25.5 months in favor of the doublet $([\mathrm{HR}]=0.82$; $\mathrm{p}=0.032$ ). Subgroup analysis showed the greatest benefit of this adjuvant doublet in a mOS in patients after radical $\mathrm{R} 0$ resection, 39.5 vs. 27.9 months $(p=0.0001)$ [19].

PRODIGE 24 is a randomized phase III multicenter trial that compared a modified mFOLFIRINOX regimen (5-FU, leucovorin, irinotecan, and oxaliplatin) and gemcitabine monotherapy in the adjuvant setting for a duration of 6 months after R0 and R1 resection. A total of 493 patients from 77 centers were enrolled and divided into two arms at a 1:1 ratio (247 patients in the mFOLFIRINOX group and 246 patients in the gemcitabine group). The median diseasefree survival (mDFS) was 21.6 vs. 12.8 months $([\mathrm{HR}]=0.58$; $\mathrm{p}<0.001)$. The mOS was also statistically significant, 54.4 vs. 34.8 months $([\mathrm{HR}]=0.64 ; \mathrm{p}=0.003)$, with results in favor of mFOLFIRINOX. Grade 3-4 toxicity was present in $75.9 \%$ vs. $52.9 \%$ of patients with gemcitabine. The planned treatment was completed in $66 \%$ of patients compared to $79 \%$ in the gemcitabine arm. In the long-term follow-up of patients, the benefit of this combination regimen was confirmed with 3 -year DFS $39.7 \%$ vs. $21.4 \%$ and 3-years OS $63.4 \%$ vs. $48.6 \%$. Thus, this study proved that the mFOLFIRINOX regimen can be safely administered in an adjuvant setting and significantly improves DFS and OS parameters compared to gemcitabine monotherapy. A modified mFOLFIRINOX regimen should be now considered as a new standard of treatment despite increased toxicity [20].

\section{Neoadjuvant chemotherapy in resectable PDAC}

Next to several retrospective analyzes and phase II trials in which the effect of gemcitabine, platinum derivatives, and 5-fluorouracil in a neoadjuvant setting has been most studied, there are also results from four recently presented clinical trials supporting a neoadjuvant approach in resectable PDAC.

The available data to date cannot be objectively compared because there are differences between the trial designs in terms of the chemotherapy regimens used, cytostatic doses 
Table 1. Advantages of the neoadjuvant approach.

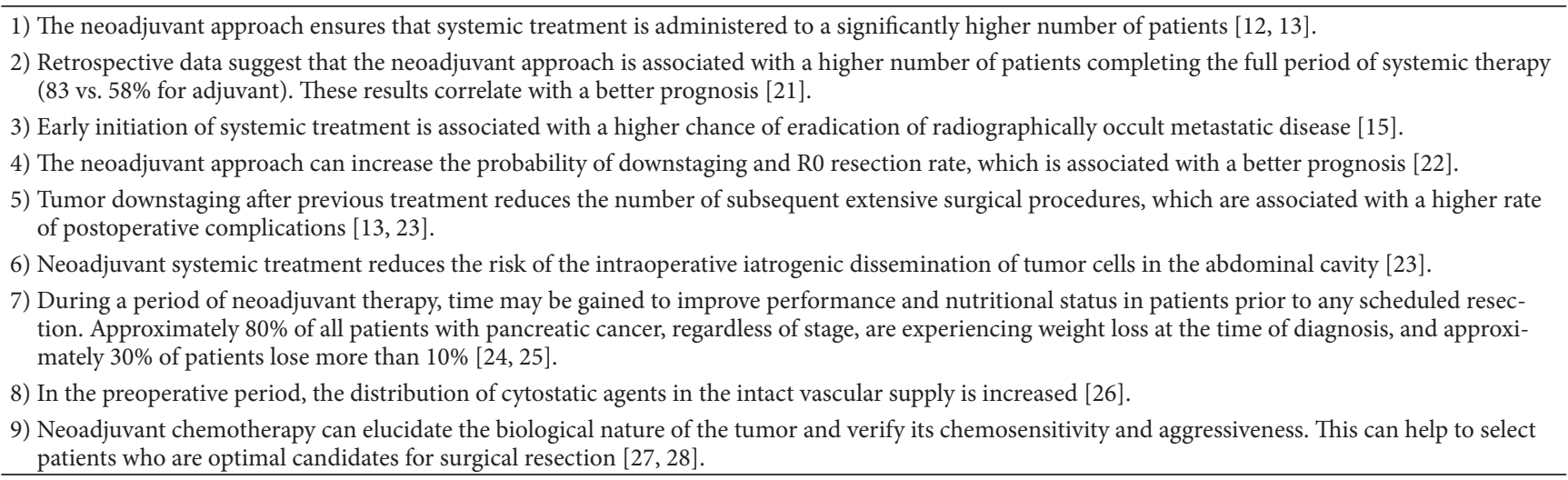

and unclear definitions of resectability. The advantages and disadvantages of neoadjuvant systemic chemotherapy for resectable PDAC are mentioned in Table $1[12,13,15$, 21-28] and Table 2 [29-32].

In a non-randomized, single-arm study by Swiss authors with neoadjuvant chemotherapy with a combination of gemcitabine and cisplatin, from a total of 28 patients with primarily resectable PDAC, resection was performed in 25 (89\%) and R0 resection was reported in 20 (80\%) cases. DFS was 9.0 months and OS 19.1 months. In addition, prealbumin levels were significantly normalized during the neoadjuvant period $(\mathrm{p}=0.008)$ [33].

O'Reilly et al. published results from 38 patients who received 4 cycles of gemcitabine and oxaliplatin in a neoadjuvant setting. 27 patients (71\%) were subsequently indicated for resection, of which 20 patients (74\%) had R0 resection. Thereafter, 5 cycles of gemcitabine were adjuvantly indicated to 26 patients. The mOS for the total population was 27.2 months. For the 27 operated patients, the median recurrence-free survival (mRFS) was 22.0 months [34].

In 2007, Palmer et al. presented results of 50 patients with a primarily resectable pancreatic tumor. They were enrolled in two arms with neoadjuvant treatment, of which 37 (74\%) had PDAC. Patients were divided into the gemcitabine monotherapy arm and the gemcitabine and cisplatin arm. The primary focus of the study was the resection rate. Eighteen $(70 \%)$ patients in the combination arm were resected vs. 9 (38\%) patients with monotherapy. The OS at 12 months for the combination and gemcitabine arm was $62 \%$ and $42 \%$ [35].

In 2017, Mokdad et al. analyzed data from the National Cancer Database (NCD) in patients treated for early-stage PDAC between 2006 and 2012. Patients with stage I and II pancreatic adenocarcinoma were compared, of which 2005 patients underwent neoadjuvant chemotherapy and 6015 patients were primarily resected. Patients were stratified by age, sex, race, date of diagnosis, economic status, performance status, $\mathrm{T}$ and $\mathrm{N}$ stage, and type of surgery. Those
Table 2. Disadvantages of the neoadjuvant approach.

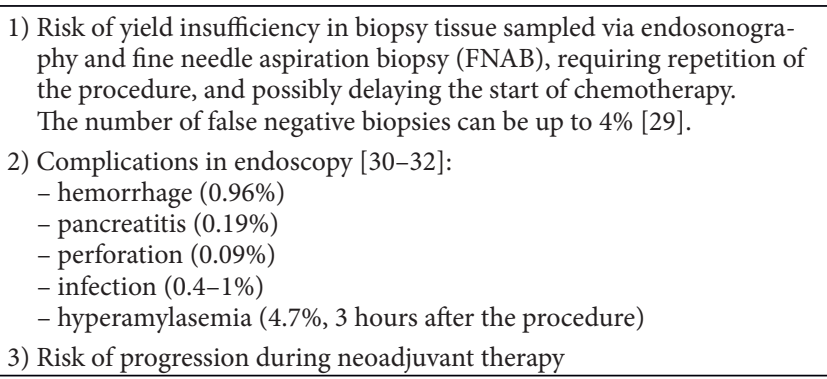

patients who underwent neoadjuvant therapy had significantly longer mOS, 26 vs. 21 months $(\mathrm{p}<0.01)$. However, only $67 \%$ of patients completed adjuvant treatment in this analysis. If this subgroup is compared to the neoadjuvant group, preoperative treatment was still associated with longer survival, the mOS was 26 vs. 23 months $(p<0.01)$. Furthermore, primarily resected patients had a higher pTNM stage (pT3/4: $86 \%$ vs. $73 \%$, p <0.01; pN+: $73 \%$ vs. $48 \%, \mathrm{p}<0.01$ ), as well as a higher rate of R1 resections ( $24 \%$ vs. $17 \%, \mathrm{p}<0.01)$. Higher $\mathrm{T}$ stage, $\mathrm{N}+$, and $\mathrm{R} 1$ resections are independent prognostic factors. Postoperative complications were similar in both groups [36]. The major limitation of this study is the fact that it is based on retrospective analysis and the fact that patients, who had been reported to have metastatic dissemination after neoadjuvant therapy were excluded from this study. A further limitation is the different chemotherapy regimens used in the neoadjuvant setting.

The data from the previous analysis may be at least partially supported by the results of another retrospective analysis from Tzeng et al. Of 115 patients who underwent neoadjuvant chemotherapy and subsequent resection, 95 (83\%) patients completed the planned treatment. In the upfront surgery group, 50 patients were analyzed and treatment was completed in 29 (58\%) of them. The most common reason for premature termination of adjuvant therapy was 
early disease progression. Completed treatment was associated with a better prognosis, the mOS was 36.0 vs. 11.0 months $(\mathrm{p}<0.001)[22]$.

Finally, a phase II-III Preop-02/JSAP-05 trial was conducted in East Asia and included 364 patients with resectable PDAC. They were randomized to either neoadjuvant gemcitabine and S-1 chemotherapy group or an upfront surgery group at a 1:1 ratio. In neoadjuvant group, patients received 2 cycles of combined chemotherapy. S-1 was administered adjuvantly for 6 months after curative resection in both arms. The primary endpoint was OS, secondary endpoints included RFS, resection rate, adverse events, nodal metastases, residual tumor status, and tumor marker kinetics. This study showed survival benefit for the neoadjuvant approach with a mOS 36.7 vs. 26.6 months $([\mathrm{HR}]=0.72 ; \mathrm{p}=0.015)$. The OS rate at 2 years was $63.7 \%$ vs. $53.5 \%$. All subgroups in this trial had a benefit from the neoadjuvant approach. Moreover, there were no significant differences in terms of surgery-related complications in both arms. However, the resection rate and $\mathrm{R} 0$ resection rate were equivalent in the two groups. The most observed grade $3 / 4$ adverse events in the neoadjuvant group were leukopenia and neutropenia $(72.8 \%)$. This trial was conducted only in Japan and S-1 chemotherapy has not been approved by the Food and Drug Administration (FDA) [37].

\section{Neoadjuvant chemoradiotherapy in resectable PDAC}

A combination of radiation and chemotherapy has become a standard treatment option for multiple types of locally advanced cancers. This combined approach can introduce a unique set of DNA aberrations, which differ from those induced by either radiation or chemotherapy alone. Gemcitabine and 5-FU are potent radiosensitizers and are commonly used concomitantly with radiation in the treatment of gastrointestinal malignancies including PDAC. Their activity is thought to be mediated via the redistribution of cells into the S-phase of the cell cycle and the depletion of nucleotide pools. The combination of these agents with radiation leads to the production of complex, slowly repaired radiation-induced DNA damage in S-phase cells, such as the 1-ended double-strand breaks produced as radiationinduced single-strand breaks collide with progressing replication forks [38].

Greer et al. published results from a retrospective review of 102 patients who underwent resection for resectable, borderline resectable, and locally advanced PDAC between 1993 and 2005 . Forty-two patients (41\%) were treated with neoadjuvant chemoradiotherapy, 41 patients $(40 \%)$ were treated with adjuvant chemoradiotherapy and 19 patients (19\%) had no additional treatment. Patients in the neoadjuvant group were more likely to have locally advanced tumors. Nevertheless, patients receiving neoadjuvant chemoradiotherapy were less likely to have a local recurrence than patients receiving adjuvant chemoradiotherapy, $5 \%$ vs. $34 \%$ ( $\mathrm{p}=0.02$ ). Among patients with resectable PDAC according to initial CT scans, local recurrences were observed in $31 \%$ (10 of 32 ) of patients in the adjuvant group compared with $7 \%$ (1 of 14) in the neoadjuvant group [39].

When chemoradiotherapy was compared to chemotherapy alone in the treatment of patients with locally advanced PDAC, grades 3 and 4 toxicities were similar, at $79 \%$ vs. $77 \%$ [40]. For resectable tumors, data are still not available.

Chemoradiotherapy has also been studied in multiple prospective clinical trials among patients with resectable PDAC. In a majority of these trials, the number of enrolled patients was not sufficient and trial design was not uniform. However, existing data are encouraging.

In 2015, Golcher et al. conducted the first randomized phase II trial with neoadjuvant concomitant chemoradiotherapy in primarily resectable PDAC. A total of 66 patients were analyzed, of which 33 were enrolled in a neoadjuvant chemoradiotherapy arm based on a combination of gemcitabine and cisplatin concomitantly with radiotherapy. Chemoradiotherapy was initiated in 29 patients. A total of 19 (58\%) patients underwent subsequent resection, which was radical in $52 \%$ of cases. In the second half of the group, 23 (70\%) patients underwent resection first, with $\mathrm{R} 0$ resections in $48 \%$ of cases. Adjuvant chemotherapy was administered in both arms. Postoperative complications were comparable in both groups. In the intent to treat (ITT) population the mOS was higher in the neoadjuvant group, 17.4 vs. 14.4 months $(p=0.96)$. After resection, the mOS was 25.0 vs. 18.9 months $(\mathrm{p}=0.79)$. The study was terminated prematurely due to slow recruitment and non-significant results [41].

Casadei et al. also investigated the effect of neoadjuvant chemoradiotherapy over primary resection. Only 38 patients were enrolled in this unicentric study, of whom 20 underwent primary resection. Neoadjuvant chemotherapy with gemcitabine alone was administered for 2 cycles followed by concomitant chemoradiotherapy for a total of 6 weeks. Chemoradiotherapy was completed in 14 out of 18 cases. The primary endpoint of the study was the R0 resection rate. However, there was no significant difference between the two groups in this parameter $(\mathrm{p}=0.489)$ [42].

Mokdad's retrospective analysis also includes data comparing neoadjuvant chemotherapy and chemoradiotherapy. Of 1326 patients, 616 had neoadjuvant chemotherapy and 710 had neoadjuvant chemoradiotherapy. OS differences were not significant between the two arms, the mOS for chemoradiotherapy and chemotherapy was 26.0 and 25.0 months, respectively $(\mathrm{p}=0.10)$. In addition, chemoradiotherapy was associated with a higher postoperative 90-day mortality rate, $7 \%$ vs. $4 \%(\mathrm{p}=0.03)$, and a higher frequency of postoperative hospitalisations, $9 \%$ vs. $6 \%(p=0.01)$. On the other hand, chemoradiotherapy was associated with a lower rate of R1 resection, $14 \%$ vs. $21 \%(\mathrm{p}=0.01)$, and node positivity, $35 \%$ vs. $59 \%(\mathrm{p}<0.01)$ [43].

The PREOPANC trial is a randomized phase III trial with neoadjuvant chemoradiotherapy for resectable or border- 
line resectable PDAC. A total of 246 eligible patients were randomized. One hundred and nineteen patients were assigned to preoperative concomitant chemoradiotherapy ( $\operatorname{arm~A)}$ and 127 to immediate surgery (arm B). Adjuvant gemcitabine was administered for 4 cycles in arm A and for 6 cycles in arm B. The primary endpoint was OS by ITT population, which was 16.0 months with preoperative chemoradiotherapy, and 14.3 months with immediate surgery $([\mathrm{HR}]=0.78 ; \mathrm{p}=0.096)$. The resection rate was $61 \%$ for the neoadjuvant group and $72 \%$ for the surgery group $(\mathrm{p}=0.058)$. The $\mathrm{R} 0$ resection rate was $71 \%(51 / 72)$ in patients who received preoperative chemoradiotherapy and $40 \%$ $(37 / 92)$ in patients assigned to immediate surgery $(\mathrm{p}<0.001)$. Preoperative chemoradiotherapy was associated with a significantly better DFS and a locoregional failure-free interval as well as with significantly lower rates of pathologic lymph nodes, perineural invasion, and venous invasion. Overall survival was improved among patients who underwent preoperative chemoradiotherapy, 35.2 vs. 19.8 months $(\mathrm{p}=0.029)$, indicating that the results were not statistically significant. Serious adverse events were comparable in both groups, $52 \%$ vs. $41 \%$ ( $\mathrm{p}=0.096$ ) [44].
Thus, the results of the trials presented are inconsistent and we still don't have clear evidence of the survival benefit of neoadjuvant chemoradiotherapy over chemotherapy alone. A summary of neoadjuvant trials is in Table $3[45,46]$.

\section{Ongoing clinical trials}

A prospective, multicenter, randomized phase II trial, PANACHE01-PRODIGE48, is evaluating the effect and safety of the two neoadjuvant regimens mFOLFIRINOX and FOLFOX (5-FU, leucovorin, and oxaliplatin) compared to adjuvant administration in resectable PDAC. The primary endpoint of this study is OS and the proportion of patients who fully complete the treatment. The study is expected to be completed in December 2021 [47].

Another ongoing trial with neoadjuvant therapy in primarily resectable PDAC is the randomized, multicenter NEONAX phase II trial comparing perioperative vs. adjuvant gemcitabine and nab-paclitaxel. This study was initiated in 2015 and the first interim results from 48 patients were presented in ASCO 2019. The plan is to include 166 patients. Two cycles of neoadjuvant chemotherapy were applied to

Table 3. Neoadjuvant trials, edited according to Janssen et al. [45] and Piatek et al. [46].

\begin{tabular}{|c|c|c|c|c|c|c|}
\hline Study author & Stage & Sample & Regimen & $\begin{array}{l}\text { Resection } \\
\text { rate [\%] }\end{array}$ & $\begin{array}{l}\mathrm{R} 0 \text { resection } \\
\text { rate }[\%]\end{array}$ & Median OS $[\mathrm{m}]$ \\
\hline \multicolumn{7}{|c|}{ Clinical trials with neoadjuvant chemoradiotherapy } \\
\hline Hoffman et al. (1998) & Resectable & 62 & $\mathrm{FU}+$ Mitomycin $+50.4 \mathrm{~Gy}$ & 45.3 & 70.8 & 16 \\
\hline Mornex et al. (2006) & Resectable & 41 & $\mathrm{PF}+50 \mathrm{~Gy}$ & 63.4 & 80.7 & 12 \\
\hline Turrini et al. (2009) & Resectable & 102 & $\mathrm{PF}+45 \mathrm{~Gy}$ & 60.8 & 91.8 & 23 \\
\hline Evans et al. (2008) & Resectable & 86 & Gem +30 Gy & 64.4 & 86.4 & 34 \\
\hline Pisters et al. (2002) & Resectable & 37 & PXL + 30 Gy (IORT) & 54.1 & 70 & 19 \\
\hline Golcher et al. (2015) & Resectable & 29 & $\mathrm{PG}+55.8 \mathrm{~Gy}$ & 65.5 & 89.5 & 25 \\
\hline Pisters et al. (1998) & Resectable & 35 & $\mathrm{FU}+30 \mathrm{~Gy}(\mathrm{IORT})$ & 57 & 51 & 37 \\
\hline Sho et al. (2013) & Resectable & 61 & Gem $+50.4-54$ Gy & 97 & 92 & NR \\
\hline Van Buren et al. (2013) & Resectable & 59 & $\mathrm{Gem}+\mathrm{Bev}+30 \mathrm{~Gy}$ & 73 & 88 & 17 \\
\hline Van Tienhoven (2020) & Resectable/BRPC & 246 & $\begin{array}{l}\text { Gem - based CHTRT + adjuv. gem } \\
\text { (A) vs. surgery + adjuv. gem (B) }\end{array}$ & $\begin{array}{l}61 \text { vs. } 72 \\
p=0.058\end{array}$ & $\begin{array}{l}71 \text { vs. } 40 \\
\text { p }<0.001\end{array}$ & $\begin{array}{l}16 \text { vs. } 14.3 \\
\mathrm{p}=0.096\end{array}$ \\
\hline \multicolumn{7}{|c|}{ Clinical trials with neoadjuvant chemotherapy } \\
\hline Palmer et al. (2007) & Resectable & 50 & Gem vs. PG & 38 vs. 70 & 75 & 28 \\
\hline Heinrich et al. (2008) & Resectable & 28 & PG & 89.3 & 80 & 27 \\
\hline O’Reilly et al. (2014) & Resectable & 38 & GemOx & 71 & 74 & 27 \\
\hline Tajima et al. (2012) & Resectable & 34 & $\mathrm{Gem}+\mathrm{S} 1$ & 100 & 85 & $56 \%$ at 24 \\
\hline Motoi et al. (2019) & Resectable & 364 & $\begin{array}{l}\text { Gem }+\mathrm{S} 1+\text { adjuv. } \mathrm{S} 1 \text { vs. } \\
\text { surgery + adjuv. } \mathrm{S} 1\end{array}$ & NR & NR & 37 vs. 27 \\
\hline \multicolumn{7}{|c|}{ Clinical trials with neoadjuvant chemotherapy and chemoradiotherapy } \\
\hline Varadhachary et al. (2008) & Resectable & 90 & $\mathrm{PG} \rightarrow 30 \mathrm{~Gy}+\mathrm{Gem}$ & 57.8 & 96.2 & 31 \\
\hline Talamonti et al. (2006) & Resectable & 20 & Gem $\rightarrow 36$ Gy & 85 & 80 & 26 (resected) \\
\hline Faris et al. (2013) & Resectable & 22 & FOLFIRINOX+/-CHTRT & 55 & 42 & NR \\
\hline Casadei et al. (2015) & Resectable & 38 & $\begin{array}{c}\text { Surgery + adjuv. gem (A) vs. Gem } \rightarrow \\
54 \text { Gy + Gem } \rightarrow \text { adjuv. gem (B) }\end{array}$ & $\begin{array}{l}75 \text { vs. } 61.1 \\
\mathrm{p}=0.489\end{array}$ & $\begin{array}{c}25 \text { vs. } 38.9 \\
\mathrm{p}=0.489\end{array}$ & $\begin{array}{l}19.5 \text { vs. } 22.4 \\
\mathrm{p}=0.973\end{array}$ \\
\hline
\end{tabular}

Abbreviations: Bev-bevacizumab; CHTRT-chemoradiotherapy; FOLFIRINOX-fluorouracil+oxaliplatin+irinotecan+leucovorin; FU-fluorouracil; Gem-gemcitabine; GemOx-gemcitabine+oxaliplatin; Gy-Gray; IORT-intraoperative radiotherapy; NR-not reportable; PF-cisplatin+fluorouracil; PG-cisplatin+gemcitabine; PXL-paclitaxel; S1-tegafur/gimeracil/oteracil; BRPC-borderline resectable pancreatic cancer 
22 patients. After a reevaluation on restaging CT, a resection was considered and then 4 cycles of adjuvant chemotherapy were applied. In the second arm, 23 patients were enrolled and up-front surgery was carried out followed by 6 cycles of adjuvant therapy. The primary endpoint is DFS at 18 months after randomization, secondary endpoints include a 3-year OS rate and DFS rate, progression during neoadjuvant therapy, R0/R1 resection rate, and quality of life. The results so far show that patients with perioperative chemotherapy have a higher rate of complications, but they were well managed and had no effect on the increase of peri- and postoperative mortality. Postoperative complications were reported in $45.0 \%$ in the neoadjuvant arm and $42.8 \%$ in the surgery arm [48].

The SWOG S1505 trial is an ongoing randomized phase II study, which includes patients with resectable PDAC. This trial is designed to determine the most promising perioperative regimen for a larger phase III trial (NCT02562716). This study has completed accrual and randomized 147 patients to 3 cycles of either perioperative mFOLFIRINOX ( $\operatorname{arm~A}$ ) or perioperative gemcitabine with nab-paclitaxel ( $\operatorname{arm~B}$ ). The primary endpoint of the study is OS at 2 years, and results are anticipated to 2020 [45]. The NorPACT- 1 trial is an ongoing multicenter study. Patients with resectable PDAC of the pancreatic head have been randomized in a 3:2 ratio to receive 4 cycles of neoadjuvant FOLFIRINOX and adjuvant 4 cycles of gemcitabine and capecitabine or upfront surgery followed by 6 cycles of adjuvant gemcitabine and capecitabine. The sample size is 90 patients, and the primary endpoint is 1-year OS for those patients who ultimately undergo a resection [49].

It can be assumed that the neoadjuvant approach could lead to a further improvement in OS and DFS in primarily resectable PDAC, and hence this may be preferred in the future. However, it should be noted that results from well-designed prospective randomized trials are currently lacking.

\section{Evaluation of radicality}

As already mentioned, one of the arguments favoring the neoadjuvant approach is the possibility of increasing the chance of R0 resection. According to several studies mentioned in Table 3, neoadjuvant therapy leads to a high probability of radical resection. R1 resection is associated with poor prognosis $[50,51]$. The cause of $\mathrm{R} 1$ may be the false negativity of perioperative cryobiopsy or the impossibility of radical surgery due to the proximity of major vessels. Evaluation of the radicality of resection is still problematic. The definition of microscopic resection margins involvement is not uniform. Prior to the introduction of a standardized pathological evaluation of the resected tissue according to the Leeds protocol, the frequency of R1 resections was $17-30 \%$ [52-54]. In the US centers, an R1 resection was defined as surface infiltration, i.e. $0 \mathrm{~mm}$ [55]. In most
European centers, the definition of an $\mathrm{R} 1$ resection is the presence of tumor cells $<1 \mathrm{~mm}$ from the edge [56]. The low frequency of R1 resections in a center is used, among other things, as an indicator of the quality of surgery.

Thus, the results of studies comparing long-term survival after R0 and R1 resections published before 2006 may be distorted by the different histopathological methodologies used at the centers. Currently, when the resected tissue is evaluated by a pathologist according to the Leeds protocol, the frequency of R1 resections is $80 \%$ [57]. Standardized evaluation best correlates with radical surgery, the frequency of local recurrences, and overall survival.

\section{Summary}

The current recommended procedure in primarily resectable PDAC is resection followed by adjuvant chemotherapy for 6 months. The PRODIGE 24 trial demonstrated the efficacy of mFOLFIRINOX that provides the longest mDFS (21.6 months) and mOS (54.4 months) of all the regimens studied in an adjuvant setting. To be noted, in this trial the population was very select. In general, $46 \%$ of patients with resected PDAC are not eligible for adjuvant therapy due to postoperative complications or very early progression. When adjuvant therapy is initiated, attention must be taken especially among patients with comorbidities. PDAC is most commonly diagnosed between the ages of 65 and 75 . Grade 3 and 4 adverse events reach up to $75.5 \%$ with an mFOLFIRINOX regimen. Therefore, an adjuvant regimen of mFOLFIRINOX is reserved for only a highly select proportion of patients with very good performance status and a minimum of comorbidities. The combination of gemcitabine and capecitabine is also associated with relatively numerous adverse reactions, especially myelotoxicity and diarrhea. Risk factors such as a large primary tumor, enlarged lymph nodes, high baseline CA 19-9 levels, significant weight loss, or severe pain can be considered indications for neoadjuvant therapy in primarily resectable patients.

Early evidence showing the efficacy of neoadjuvant therapy in patients with resectable PDAC is already available. The main goal of this approach is to increase the number of patients treated with systemic therapy, as well as to reach downstaging, and to increase the likelihood of $\mathrm{R} 0$ resections. Moreover, early initiation of systemic treatment can eradicate the micrometastatic disease. The use of chemoradiotherapy in a neoadjuvant setting is associated with a higher R0 resection rate, but not with significant improvement in overall survival.

In conclusion, the treatment of resectable PDAC should be multidisciplinary and concentrated in high-volume centers. It is necessary to evaluate the approach to treatment individually based on the tumor stage, the patient's performance status, and comorbidities. Radical resection is the only curative-intent treatment, but post-operative morbidity and mortality is still relatively high. The current 
standard of care in this setting is up-front surgery with adjuvant chemotherapy. Despite selection bias affecting survival outcomes in neoadjuvant compared to adjuvant trials, patients enrolled in the neoadjuvant trials seem to benefit from this approach. Neoadjuvant treatment can improve patient selection and identify those who can benefit from resection. Moreover, systemic treatment prior to surgery can help apply cytostatics to a much larger population and eliminate radiographically occult metastatic lesions. Ongoing clinical trials are investigating the effect of the multi-agent regimen FOLFIRINOX in a neoadjuvant setting.

\section{References}

[1] CASCINU S, FALCONI M, VALENTINI V, JELIC S. Pancreatic cancer: ESMO Clinical Practice Guidelines for diagnosis, treatment and follow-up. Ann Oncol 2010; 21: 55-58. https://doi.org/10.1093/annonc/mdq165

[2] BRAY F, FERLAY J, SOERJOMATARAM I, SIEGEL RL, TORRE LA et al. Global cancer statistics 2018: GLOBOCAN estimates of incidence and mortality worldwide for 36 cancers in 185 countries. CA Cancer J Clin 2018; 68: 394-424. https://doi.org/10.3322/caac.21492

[3] DUSEK L, MUZIK J, KUBASEK M, KOPTIKOVA J, ZALOUDIK J et al. Epidemiology of Malignant Tumours in the Czech Republic [online]. Masaryk University, Czech Republic, [2005], [cit. 2020-5-31]. http://www.svod.cz. Version 7.0 [2007], ISSN 1802-8861.

[4] WU W, HE X, YANG L, WANG Q, BIAN X et al. Rising trends in pancreatic cancer incidence and mortality in 2000-2014. Clin Epidemiol 2018; 10: 789-797. https://doi. org/10.2147/CLEP.S160018

[5] HOWLADER N, NOONE AM, KRAPCHO M, MILLER D, BISHOP K et al. SEER Cancer Statistics Review, 1975-2014, National Cancer Institute. Bethesda, MD, https://seer.cancer. gov/csr/1975_2014/, based on November 2016 SEER data submission, posted to the SEER web site, April 2017.

[6] CARDINI B, PRIMAVESI F, MAGLIONE M, OBERSCHMIED J, GUSCHLBAUER L et al. Outcomes following pancreatic resections-results and challenges of an Austrian university hospital compared to nationwide data and international centres. Eur Surg 2019; 51: 81-89. https://doi. org/10.1007/s10353-019-0585-x

[7] ALOIA TA, LEE JE, VAUTHEY JN, ABDALLA EK, WOLFF RA et al. Delayed Recovery after Pancreaticoduodenectomy: A Major Factor Impairing the Delivery of Adjuvant Therapy? J Am Coll Surg 2007; 204: 347-355. https://doi.org/10.1016/j. jamcollsurg.2006.12.011

[8] LABORI KJ, KATZ MH, TZENG CW, BJØRNBETH BA, CVANCAROVA $M$ et al. Impact of early disease progression and surgical complications on adjuvant chemotherapy completion rates and survival in patients undergoing the surgery first approach for resectable pancreatic ductal adenocarcinoma - A population-based cohort study. Acta Oncol 2016; 55: 265-277. https://doi.org/10.3109/0284186X.2015.1068445
[9] GROOT VP, REZAEE N, WU W, CAMERON JL, FISHMAN EK et al. Patterns, Timing, and Predictors of Recurrence Following Pancreatectomy for Pancreatic Ductal Adenocarcinoma. Ann Surg 2018; 267: 936-945. https://doi. org/10.1097/SLA.0000000000002234

[10] CHANG MC, WONG JM, CHANG YT. Screening and early detection of pancreatic cancer in high risk population. World J Gastroenterol. 2014; 20: 2358-2364. https://doi. org/10.3748/wjg.v20.i9.2358

[11] TEMPERO MA, MALAFA MP, AL-HAWARY M, ASBUN $\mathrm{H}$, BAIN A et al. Pancreatic Adenocarcinoma, Version 2.2017, NCCN Clinical Practice Guidelines in Oncology. J Natl Compr Canc Netw 2017; 15: 1028-1061. https://doi. org/10.6004/jnccn.2017.0131

[12] BAKENS MJ, VAN DER GEEST LG, VAN PUTTEN M, VAN LAARHOVEN HW, CREEMERS GJ et al. The use of adjuvant chemotherapy for pancreatic cancer varies widely between hospitals: a nationwide population-based analysis. Cancer Med 2016; 5(10): 2825-2831. https://doi. org/10.1002/cam4.921

[13] SPITZ FR, ABBRUZZESE JL, LEE JE, PISTERS PW, LOWY $A M$ et al. Preoperative and postoperative chemoradiation strategies in patients treated with pancreaticoduodenectomy for adenocarcinoma of the pancreas. J Clin Oncol 1997; 15: 928-937. https://doi.org/10.1200/JCO.1997.15.3.928

[14] BELLI C, CEREDA S, ANAND S, RENI M. Neoadjuvant therapy in resectable pancreatic cancer: a critical review. Cancer Treat Rev 2013; 39: 518-524. https://doi.org/10.1016/j. ctrv.2012.09.008

[15] HAENO H, GONEN M, DAVIS MB, HERMAN JM, IACOBUZIO-DONAHUE CA et al. Computational modeling of pancreatic cancer reveals kinetics of metastasis suggesting optimum treatment strategies. Cell 2012; 148: 362-375. https://doi.org/10.1016/j.cell.2011.11.060

[16] NEOPTOLEMOS JP, STOCKEN DD, FRIESS H, BASSI C, DUNN JA et al. A randomized trial of chemoradiotherapy and chemotherapy after resection of pancreatic cancer. $\mathrm{N}$ Engl J Med 2004; 350: 1200-1210. https://doi.org/10.1056/ NEJMoa032295

[17] OETTLE H, POST S, NEUHAUS P, GELLERT K, LANGREHR J et al. Adjuvant Chemotherapy With Gemcitabine vs Observation in Patients Undergoing Curative-Intent Resection of Pancreatic Cancer: A Randomized Controlled Trial. JAMA 2007; 297: 267-277. https://doi.org/10.1001/ jama.297.3.267

[18] OETTLE H, NEUHAUS P, HOCHHAUS A, HARTMANN JT, GELLERT K et al. Adjuvant Chemotherapy With Gemcitabine and Long-term Outcomes Among Patients With Resected Pancreatic Cancer: The CONKO-001 Randomized Trial. JAMA 2013; 310: 1473-1481. https://doi.org/10.1001/ jama.2013.279201

[19] NEOPTOLEMOS JP, PALMER DH, GHANEH P, PSARELLI EE, VALLE JW et al. Comparison of adjuvant gemcitabine and capecitabine with gemcitabine monotherapy in patients with resected pancreatic cancer (ESPAC-4): a multicentre, open-label, randomised, phase 3 trial. Lancet 2017; 389: 1011-1024. https://doi.org/10.1016/S0140-6736(16)32409-6 
[20] CONROY T, HAMMEL P, HEBBAR M, BEN ABDELGHANI M, WEI AC et al. FOLFIRINOX or Gemcitabine as Adjuvant Therapy for Pancreatic Cancer. N Engl J Med 2018; 379: 2395-2406. https://doi.org/10.1056/NEJMoa1809775

[21] TZENG CW, TRAN CAO HS, LEE JE, PISTERS PW, VARADHACHARY GR et al. Treatment sequencing for resectable pancreatic cancer: influence of early metastases and surgical complications on multimodality therapy completion and survival. J Gastrointest Surg 2014; 18: 16-24. https://doi. org/10.1007/s11605-013-2412-1

[22] FATIMA J, SCHNELLDORFER T, BARTON J, WOOD CM, WISTE HJ et al. Pancreatoduodenectomy for ductal adenocarcinoma: Implications of positive margin on survival. Arch Surg 2010; 145: 167-172. https://doi.org/10.1001/archsurg.2009.282

[23] TAJIMA H, MAKINO I, OHBATAKE Y, NAKANUMA S, HAYASHI $\mathrm{H}$ et al. Neoadjuvant chemotherapy for pancreatic cancer: Effects on cancer tissue and novel perspectives. Oncol Lett 2017; 13: 3975-3981. https://doi.org/10.3892/ ol.2017.6008

[24] BYE A, JORDHØY MS, SKJEGSTAD G, LEDSAAK O, IVERSEN PO et al. Symptoms in advanced pancreatic cancer are of importance for energy intake. Support Care Cancer 2013; 21: 219-227. https://doi.org/10.1007/s00520-0121514-8

[25] DAVIDSON W, ASH S, CAPRA S, BAUER J, CANCER CACHEXIA STUDY GROUP. Weight stabilisation is associated with improved survival duration and quality of life in unresectable pancreatic cancer. Clin Nutr 2004; 23: 239-247. https://doi.org/10.1016/j.clnu.2003.07.001

[26] ASSIFI MM, LU X, EIBL G, REBER HA, LI G et al. Neoadjuvant therapy in pancreatic adenocarcinoma: a meta-analysis of phase II trials. Surgery 2011; 150: 466-473. https://doi. org/10.1016/j.surg.2011.07.006

[27] CARPELAN-HOLMSTRÖM M, NORDLING S, PUKKALA E, SANKILA R, LÜTTGES J et al. Does anyone survive pancreatic ductal adenocarcinoma? A nationwide study re-evaluating the data of the Finnish Cancer Registry. Gut 2005; 54: 385-387. https://doi.org/10.1136/gut.2004.047191

[28] BILIMORIA KY, BENTREM DJ, KO CY, STEWART AK, WINCHESTER DP et al. National failure to operate on early stage pancreatic cancer. Ann Surg 2007; 246: 173-180. https://doi.org/10.1097/SLA.0b013e3180691579

[29] ELOUBEIDI MA, JHALA D, CHHIENG DC, CHEN VK, ELTOUM I et al. Yield of endoscopic ultrasound-guided fine-needle aspiration biopsy in patients with suspected pancreatic carcinoma. Cancer 2003; 99: 285-292. https://doi. org/10.1002/cncr.11643

[30] CARRARA S, ARCIDIACONO PG, MEZZI G, PETRONE MC, BOEMO C et al. Pancreatic endoscopic ultrasoundguided fine needle aspiration: complication rate and clinical course in a single centre. Dig Liver Dis 2010; 42: 520-523. https://doi.org/10.1016/j.dld.2009.10.002

[31] ADLER DG, JACOBSON BC, DAVILA RE, HIROTA WK, LEIGHTON JA et al. ASGE guideline: complications of EUS. Gastrointest Endosc 2005; 61: 8-12. https://doi.org/10.1016/ s0016-5107(04)02393-4
[32] WANG KX, SUN SY, SHENG J, ZHAN XB, YANG AM et al. Incidence of hyperamylasemia after endoscopic ultrasound-guided fine needle aspiration of pancreatic lesions: a multicenter study from China. Pancreas 2012; 41: 712-716. https://doi.org/10.1097/MPA.0b013e31823e70cb

[33] HEINRICH S, PESTALOZZI BC, SCHÄFER M, WEBER A, BAUERFEIND $P$ et al. Prospective phase II trial of neoadjuvant chemotherapy with gemcitabine and cisplatin for resectable adenocarcinoma of the pancreatic head. J Clin Oncol 2008; 26: 2526-2531. https://doi.org/10.1200/ JCO.2007.15.5556

[34] O'REILLY EM, PERELSHTEYN A, JARNAGIN WR, SCHATTNER M, GERDES H et al. A single-arm, nonrandomized phase II trial of neoadjuvant gemcitabine and oxaliplatin in patients with resectable pancreas adenocarcinoma. Ann Surg 2014; 260: 142-148. https://doi.org/10.1097/ SLA.0000000000000251

[35] PALMER DH, STOCKEN DD, HEWITT H, MARKHAM $\mathrm{CE}, \mathrm{HASSAN} \mathrm{AB}$ et al. A randomized phase 2 trial of neoadjuvant chemotherapy in resectable pancreatic cancer: gemcitabine alone versus gemcitabine combined with cisplatin. Ann Surg Oncol 2007; 14: 2088-2096. https://doi. org/10.1245/s10434-007-9384-x

[36] MOKDAD AA, MINTER RM, ZHU H, AUGUSTINE MM, POREMBKA MR et al. Neoadjuvant Therapy Followed by Resection Versus Upfront Resection for Resectable Pancreatic Cancer: A Propensity Score Matched Analysis. J Clin Oncol 2017; 35: 515-522. https://doi.org/10.1200/ JCO.2016.68.5081

[37] MOTOI F, KOSUGE T, UENO H, YAMAUE H, SATOI S et al. Randomized phase II/III trial of neoadjuvant chemotherapy with gemcitabine and S-1 versus upfront surgery for resectable pancreatic cancer (Prep-02/JSAP05). Jpn J Clin Oncol 2019; 49: 190-194. https://doi.org/10.1093/jjco/ hyy 190

[38] MORGAN MA, PARSELS LA, MAYBAUM J, LAWRENCE TS. Improving the efficacy of chemoradiation with targeted agents. Cancer Discov. 2014; 4: 280-291. https://doi. org/10.1158/2159-8290.CD-13-0337

[39] GREER SE, PIPAS JM, SUTTON JE, ZAKI BI, TSAPAKOS $\mathrm{M}$ et al. Effect of neoadjuvant therapy on local recurrence after resection of pancreatic adenocarcinoma. J Am Coll Surg. 2008; 206: 451-457. https://doi.org/10.1016/j.jamcollsurg.2007.10.002

[40] LOEHRER PJ SR, FENG Y, CARDENES H, WAGNER L, BRELL J et al. Gemcitabine alone versus gemcitabine plus radiotherapy in patients with locally advanced pancreatic cancer: an Eastern Cooperative Oncology Group trial. J Clin Oncol. 2011; 29: 4105-4112. https://doi.org/10.1200/ JCO.2011.34.8904

[41] GOLCHER H, BRUNNER TB, WITZIGMANN H, MARTI L, BECHSTEIN WO et al. Neoadjuvant chemoradiation therapy with gemcitabine/cisplatin and surgery versus immediate surgery in resectable pancreatic cancer: results of the first prospective randomized phase II trial. Strahlenther Onkol 2015; 191: 7-16. https://doi.org/10.1007/s00066-0140737-7 
[42] CASADEI R, DI MARCO M, RICCI C, SANTINI D, SERRA $\mathrm{C}$ et al. Neoadjuvant Chemoradiotherapy and Surgery Versus Surgery Alone in Resectable Pancreatic Cancer: A SingleCenter Prospective, Randomized, Controlled Trial Which Failed to Achieve Accrual Targets. J Gastrointest Surg 2015; 19(10): 1802-1812. https://doi.org/10.1007/s11605-0152890-4

[43] MOKDAD AA, MINTER RM, YOPP AC, POREMBKA MR, WANG SC et al. Comparison of Overall Survival Between Preoperative Chemotherapy and Chemoradiotherapy for Resectable Pancreatic Adenocarcinoma. J Natl Compr Canc Netw 2018; 16(12): 1468-1475. https://doi.org/10.6004/ jnccn.2018.7068

[44] VERSTEIJNE E, SUKER M, GROOTHUIS K, AKKERMANS-VOGELAAR JM, BESSELINK MG et al. Preoperative Chemoradiotherapy Versus Immediate Surgery for Resectable and Borderline Resectable Pancreatic Cancer: Results of the Dutch Randomized Phase III PREOPANC Trial. J Clin Oncol 2020; 38: 1763-1773. https://doi.org/10.1200/ JCO.19.02274

[45] JANSSEN QP, O'REILLY EM, VAN EIJCK CHJ, GROOT KOERKAMP B. Neoadjuvant Treatment in Patients With Resectable and Borderline Resectable Pancreatic Cancer. Front Oncol 2020; 10: 41. https://doi.org/10.3389/fonc.2020.00041

[46] PIĄTEK M, KUŚNIERZ K, BIEŃKOWSKI M, PĘKSA R, KOWALCZYK $M$ et al. Primarily resectable pancreatic adenocarcinoma - to operate or to refer the patient to an oncologist? Crit Rev Oncol Hematol 2019; 135: 95-102. https:// doi.org/10.1016/j.critrevonc.2019.01.010

[47] SCHWARZ L, VERNEREY D, BACHET JB, TUECH JJ, PORTALES $\mathrm{F}$ et al. Resectable pancreatic adenocarcinoma neo-adjuvant FOLF(IRIN)OX-based chemotherapy - a multicenter, non-comparative, randomized, phase II trial (PANACHE01-PRODIGE48 study). BMC Cancer 2018; 18: 762. https://doi.org/10.1186/s12885-018-4663-4

[48] ETTRICH TJ, BERGER AW, PERKHOFER L, DAUM S, KÖNIG A et al. Neoadjuvant plus adjuvant or only adjuvant nab-paclitaxel plus gemcitabine for resectable pancreatic cancer - the NEONAX trial (AIO-PAK-0313), a prospective, randomized, controlled, phase II study of the AIO pancreatic cancer group. BMC Cancer 2018; 18(1): 1298. https:// doi.org/10.1186/s12885-018-5183-y
[49] LABORI KJ, LASSEN K, HOEM D, GRØNBECH JE, SØREIDE JA et al. Neoadjuvant chemotherapy versus surgery first for resectable pancreatic cancer (Norwegian Pancreatic Cancer Trial - 1 (NorPACT-1)) - study protocol for a national multicentre randomized controlled trial. BMC Surg 2017; 17: 94. https://doi.org/10.1186/s12893-017-0291-1

[50] GARCEA G, DENNISON AR, PATTENDEN CJ, NEAL CP, SUTTON CD et al. Survival following curative resection for pancreatic ductal adenocarcinoma. A systematic review of the literature. JOP 2008; 9: 99-132.

[51] NEOPTOLEMOS JP, STOCKEN DD, DUNN JA, ALMOND J, BEGER HG et al. Influence of resection margins on survival for patients with pancreatic cancer treated by adjuvant chemoradiation and/or chemotherapy in the ESPAC-1 randomized controlled trial. Ann Surg 2001; 234: 758-768. https://doi.org/10.1097/00000658-200112000-00007

[52] VERBEKE CS, SMITH AM. Survival after pancreaticoduodenectomy is not improved by extending resections to achieve negative margins. Ann Surg 2010; 251: 776-777; author reply 777-778. https://doi.org/10.1097/SLA.0b013e3181d57af6

[53] ESPOSITO I, KLEEFF J, BERGMANN F, REISER C, HERPEL E et al. Most pancreatic cancer resections are R1 resections. Ann Surg Oncol 2008; 15: 1651-1660. https://doi. org/10.1245/s10434-008-9839-8

[54] DELPERO JR, BACHELLIER P, REGENET N, LE TREUT YP, PAYE F et al. Pancreaticoduodenectomy for pancreatic ductal adenocarcinoma: a French multicentre prospective evaluation of resection margins in 150 evaluable specimens. HPB (Oxford) 2014; 16: 20-33. https://doi.org/10.1111/ hpb. 12061

[55] RAUT CP, TSENG JF, SUN CC, WANG H, WOLFF RA et al. Impact of resection status on pattern of failure and survival after pancreaticoduodenectomy for pancreatic adenocarcinoma. Ann Surg 2007; 246: 52-60. https://doi. org/10.1097/01.sla.0000259391.84304.2b

[56] CAMPBELL F, CARINS A, editors. Dataset for histopatological reporting of carcinomas of the pancreas, ampulla of Vater and common bile duct. London: The Royal College of Pathologists, 2019

[57] STROBEL O, HANK T, HINZ U, BERGMANN F, SCHNEIDER L et al. Pancreatic Cancer Surgery: The New Rstatus Counts. Ann Surg 2017; 265: 565-573. https://doi. org/10.1097/SLA.0000000000001731 